6. Тараненко, О.О. Варіанти мовних одиниць / О.О. Тараненко // Українська мова: енциклопедія / редкол. В. М. Русанівський, О. О. Тараненко (співголови), М. П. Зяблюк та ін. - К. : Вид-во «Українська енциклопедія» ім. М. П. Бажана, 2004. - С. 62-63.

7. Український правопис / Ін-т мовознавства ім. О. О. Потебні НАН України, Ін-т української мови НАН України. - К. : Наук. думка, 2015. - 288 с.

8. Фунікова, Т. В. Становлення флексій давального та місцевого відмінків іменників чоловічого роду в українській літературній мові XVII ст. (на матеріалі «Синопсису» та «Хроніки» Ф. Софоновича) / Т. В. Фунікова // Вісник Харківського національного університету імені В. Н. Каразіна. Серія Філологія. № 994. Вип. 64. - Харків, 2012. - С. 28-34.

9. Ярошенко, В. Українська мова в молдавських грамотах XIV-XV ст. / В. Ярошенко // Збірник Комісії для дослідження старої української мови. - Т. 1. - K., 1931. - C. 247-338.

10. Kuraszkiewicz, W. Gramoty halicko-wolyńskie XIV-XV wieku / W. Kuraszkiewicz. - Kraków : Skłąd Główny : Gebethner i Wolff, 1934. - 173 p.

Стаття надійшла 07.04.2016 року

УДК $81 ’ 246.2+81 ’ 255.2$

Надежда Никитина

(Минск, Республика Беларусь)

\title{
О СТАТУСЕ АВТОРСКОГО ПЕРЕВОДА В КОНТЕКСТЕ СИТУАЦИИ БИЛИНГВИЗМА
}

В статье рассматриваются проблемы статуса авторского перевода, его связи с мышлением и поведением билингвальной языковой личности, устанавливаются причины обращения авторов к самостоятельному переводу своих произведений, а также факт правомерности изменений, вносимых в текст оригинала при авторском переводе. Предпринята попьтка обобщить существующие взгляды на лингвистическую сущность, коммуникативную и художественную значимость авторского перевода. В статье представлен иирокий обзор отечественных $u$ зарубежных источников по проблемам изучения авторского перевода.

Ключевые слова: авторский перевод, билингвизм, билингвальная языковая личность, внутренний конфликт, интерференция, коммуникация.

\footnotetext{
Нікітіна Н. Про статус авторського перекладу в контексті ситуації білінгвізму.

У статті розглядаються проблеми статусу авторського перекладу, його зв'язки з мисленням та поведінкою білінгвальної мовної особистості, встановлюються причини звернення авторів до самостійного переведення свойх творів, а також факт правомірності змін, внесених у текст оригіналу при авторському перекладі. Зроблена спроба узагальнити існуючі погляди на лінгвістичну сутність, комунікативну та художню значимість авторського перекладу. У статті
} 
представлений широкий огляд вітчизняних та зарубіжних джерел з проблем вивчення авторського перекладу.

Ключові слова: авторський переклад, білінгвізм, білінгвальна мовна особистість, інтерференція, комунікація, внутрішній конфлікт.

Nikitina $N$. The status of self-translation in the context of bilingual situation.

The article deals with the problem of the status of self-translation, of its connection with the thinking and behavior of bilingual linguistic personality. The state of internal conflict of self-translators is described on the basis of psychological, sociolinguistic, neuropsychological observations of bilinguals. The reasons (socio-political, ideological, individual etc.) for the authors' issuing for unaided translation of their works are established, as well as the fact of the legality of the original text corrections during the selftranslation. The author argues that in the case of self-translation writers can make the «legitimate» changes that alter the subject of the text, and «unlawful» changes, which include the existence of cross-language interference. The author makes an attempt to summarize the current views on the nature of linguistic, communicative and artistic significance of self-translation. The article provides a broad overview of domestic and foreign sources on the problem of self-translation.

Keywords: self-translation, bilingualism, bilingual linguistic personality, interference, communication, internal conflict.

В современном языкознании, литературоведении, теории коммуникации неоднозначно решается вопрос о том, что представляет собой авторский перевод (АП), т. е. перевод художественного произведения, осуществленный самим его создателем. Долгое время он считался лишь одним из проявлений двуязычия личности, средством представления созданного писателем творения на другом, отличном от оригинала языке. Науке еще предстоит дать полные и по возможности однозначные ответы на вопросы о сущности АП и его особенностях, мы же ставим целью данной статьи обобщить существующие взгляды на эти проблемы. В ходе исследования необходимо решить ряд задач: систематизировать мнения ученых, переводчиков и писателей о статусе АП, его связи с мышлением и поведением билингвальной языковой личности, установить причины обращения авторов к самостоятельному переводу своих произведений, а также факт правомерности изменений, вносимых в текст оригинала при АП.

Очевидно, что авторский перевод является результатом деятельности билингвальной языковой личности, живущей и творящей, как правило, в условиях билингвизма. Теория билингвизма достаточно разработана в трудах отечественных и зарубежных исследователей. Однако это явление представляет собой многоаспектную проблему, выступает объектом изучения ряда научных дисциплин, вследствие чего не имеет единой дефиниции. 
Классическим считается определение У. Вайнрайха, который называет билингвизмом «владение двумя языками и попеременное их использование в зависимости от условий речевого общения» [10, с. 22]. Очевидно, что при таких условиях владение обоими языками должно быть достаточно свободным, чтобы участники коммуникации могли достичь взаимопонимания. Однако в большинстве известных определений билингвизма эта особенность не оговаривается.

В. П. Рагойша понимает под двуязычием «такую степень активного владения индивидом, кроме основного, вторым языком, которая обеспечивает ему полноценное восприятие художественного произведения, написанного на этом (втором) языке. Полноценно воспринимать - это значит не только понимать смысл произведения, но и получать от прочитанного эстетическое удовлетворение» [13, с. 38]. Это определение может быть дополнено ссылкой на способность билингва не только воспринимать, но и создавать художественные тексты на двух языках. В таком случае уместно говорить о художественном билингвизме, одним из типов которого является АП.

Четких границ между понятиями «авторский перевод» и «билингвальное творчество» не существует, как не существует общепринятого понимания статуса АП. Теоретики и практики перевода не смогли пока прийти к единому мнению в отношении сущности АП.

Во-первых, большинство лингвистов и мастеров слова (М. А. Апышев (Кыргызстан), Э. Бандин Фуэртес (Испания), С. Дубински (Франция), О. П. Погинайко (Украина), В. П. Рагойша (Беларусь); галисийский прозаик Э. Бланко-Амор, канадская писательница Н. Хьюстон и др.) воспринимают АП как новую редакцию оригинального произведения, процесс и результат его творческого переосмысления, воссоздания. В пользу этой точки зрения говорит возможность автора, в отличие от профессионального переводчика, вносить в текст оригинала изменения и дополнения, порой весьма существенно меняющие его внешнюю и внутреннюю форму.

Во-вторых, можно рассматривать процесс АП как оригинальное творчество, а его результат - как вариант художественного произведения, равнозначный оригиналу. Сторонники этого подхода

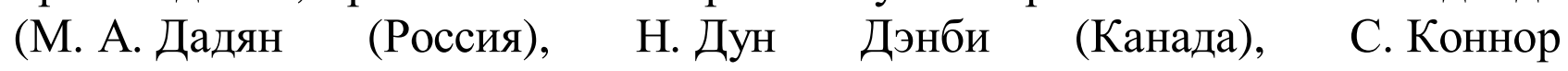
(Великобритания); франко-американский прозаик Р. Федерман и др.) считают, что каждая версия текста имеет силу и должна быть включена в читательскую оценку и интерпретацию работы, поскольку они обе произведены одним автором. Сами авторы-переводчики (южноафриканский прозаик А. Бринк, каталонско-французский писатель Ж.-И. Казанова и др.) полагали, что не переводят свои произведения, а пишут одно произведение дважды на двух языках, и в итоге не могли 
определить, какой из вариантов является оригиналом, а какой - АП. В связи с этим возможно считать АП частью «двуязычного текста», которая не является завершенной без другой части, выполненной на втором языке.

Еще один подход связан с отождествлением АП с обычным переводом. А. А. Гируцкий (Беларусь), А. Попович (Словакия), А. Сиу Вай Фун (Китай), Э. Танкейро (Испания)и др. считают, что авторыпереводчики действуют больше как переводчики, чем как авторы. Они находятся в привилегированном положении, но их истинные намерения уже определены в оригинале, они неизменны. Поэтому АП «с точки зрения процесса творчества представляет собой разновидность перевода, а не оригинального творчества» [8, с. 77].

Синкретичного подхода к определению статуса АП придерживаются М. Устинофф (Франция), Т. Чебан (Румыния), Н. В. Яковенко (Денисова) из Беларуси. По их мнению, АП одновременно является видом литературного творчества и формой художественного перевода.

В. Коллер (Германия), Я. Мохдеб (Франция) выступают за придание АП уникального стамуса, поскольку это «ни перевод, ни переписывание» [19]. Французский переводчик Я. Мохдеб при определении статуса АП основывается на их типологии по времени создания. Он сравнивает одновременный АП с сиамскими близнецами, а отложенный во времени - с обычными близнецами. «Сиамские» тексты дополняют друг друга, их нельзя разделить без нанесения ущерба. Что касается текстов-близнецов, их разделение не вредит их пониманию. Родство между ними бесспорно, но разница во времени обусловливает то, что второй текст кажется дубликатом первого, чьи различные аспекты были изменены со временем [19].

Азербайджанский и российский писатель, переводчик и ученый Ч. Г. Гусейнов, в свою очередь, опирается на типологию АП по степени соответствия оригиналу. С его точки зрения, адекватный АП идентичен профессиональному, а в результате вольного перевода появляется новый оригинал на другом языке [11, с. 145].

Итак, несмотря на неоднозначный статус АП, в основе данного явления, безусловно, лежит билингвизм. Степень владения двумя языками - это лишь один из многочисленных аспектов билингвизма [5, с. 27], раскрыть которые лингвистика может при условии сотрудничества с другими науками: психологией, социологией, психолингвистикой, логопедией, методикой преподавания иностранных языков и т. д.

Например, психологический аспект билингвизма включает изучение механизмов производства и восприятия речи. Доказано, что у билингвальной языковой личности существует единая система восприятия и две отдельные системы речепроизводства на родном и неродном языках $[1$, с. 36]. 
Что касается связи языка и мышления, то, по мнению У. Вайнрайха, «когда между семантемами контактирующих языков устанавливается межъязыковая идентификация, двуязычный человек получает возможность интерпретировать те два знака, семантемы (означаемые), которые он отождествляет как один составной знак, имеющий одно обозначаемое и два обозначающих - в каждом языке свое» [5, с. 46].

Принимая во внимание социолингвистический аспект изучения двуязычия можно допустить, что билингв, свободно владея двумя языками, рассматривает второй язык как метаязык [4, с. 51], и данное утверждение представляется особенно верным в отношении двуязычного писателя, который выступает носителем художественного билингвизма.

Еще в 20-х гг. XX в. Л. С. Выготский, исследуя проблему многоязычия у детей, описывал наблюдения советского невропатолога Е.К. Сеппа над билингвами, которые при афазии (разрушении определенного участка коры головного мозга) теряют способность говорить на родном языке, однако свободно владеют вторым, употреблявшимся до болезни в меньшей степени. Л. С. Выготский делает вывод об относительной самостоятельности каждой из языковых систем, их непосредственной связи с мышлением и функциональной взаимной борьбе [7, с. 61].

Как сказано выше, писатели-билингвы обладают своеобразным мышлением, синтезирующим в себе черты национальной картины мира обоих языков, которыми они владеют. По свидетельствам ряда авторов (азербайджанский прозаик Анар, марийский писатель К. Васин, Н. Хьюстон), билингвы испытывают затруднения, связанные с образным, художественным мышлением на втором родном языке. При написании текстов публицистического или научного содержания подобных трудностей не возникает. Н. Хьюстон предполагает, что зоны, отвечающие за владение каждым из языков, располагаются в разных полушариях головного мозга билингва: «Весь мой французский находится в левом полушарии моего мозга - его гипер-рациональной и структурированной части. В то время как правая часть - более целостная, художественная и эмоциональная - полностью английская ${ }^{*} »[17$, с. 57].

Понятие соперничества (борьбы) также лежит в основе одной из моделей порождения речи у билингвов, разработанной американским психологом Б. МакУинни в начале XXI в. Эта своеобразная борьба происходит на уровнях фонологии, лексики, морфологии, синтаксиса и концептуализации, каждый из которых обслуживается разным сочетанием нейронных связей [10, с. 108].

\footnotetext{
Английский - родной язык для Н. Хьюстон, французский она начала изучать лишь в студенческие годы.
} 
Современные нейропсихологические исследования показывают, что «при конфликте между языками в ситуации лексического выбора в процессе порождения речи мозг билингва реагирует иначе, чем мозг монолингва. Для разрешения лексического конфликта активируется та система мозга, которая обычно специализируется на разрешении любых конфликтов, но не участвует в порождении речи» [3, с. 64].

Таким образом, в процессе порождения речи билингвальная языковая личность находится в состоянии внутреннего конфликта, связанного с необходимостью выбора корректного речевого поведения - одной из двух языковых систем, за работу которых отвечают разные зоны головного мозга.

Говоря о психологическом состоянии авторов-переводчиков, можно предположить, что причина их внутреннего конфликта кроется в недостаточности обоих языков. Недостаточность одного языка восполняется другим, следовательно, две языковые версии художественного произведения составляют цельный текст. Наличие гипотетического единого текста позволяет предположить, что писательпереводчик объединяет две формы гипотетической единой личности, которые дополняют друг друга и составляют одну творческую литературную личность [16]. В процессе внутренней борьбы двойственной языковой личности АП выполняет роль переговоров между двумя ее сторонами, источника их примирения в виде литературного творчества [17, с. 58].

В творческой среде существуют писатели-билингвы и писателипереводчики, но отнюдь не все они обращаются к переводу собственных произведений, рассматривая АП как отрицательную практику (осетинский поэт и прозаик Т. Бесаев, белорусский писатель Я. Брыль, алжирская писательница А. Джебар, галисийский автор М. Ривас, французский и испанский писатель Х. Семпрун и др.). Большинство ссылается при этом на нежелание проделывать дважды одну и ту же работу (канадская писательница М. Галлант, С. Кенз Аль Фарах (палестинская писательница, живущая во Франции), итальянский писатель и переводчик А. Табукки и др.). Даже белорусский прозаик В. Козько, переводивший свои произведения только самостоятельно, считал, что «пересоздание идет по уже вспаханному, хорошо ли, плохо ли, но обработанному уже» [11, c. 151].

По мнению большинства практиков АП, это «двуликий опыт», не всегда приносящий удовлетворение. Отсюда - метафорические ассоциации АП с «проигранной битвой» (ирландский писатель, поэт и драматург С. Беккет), «падением между двух стульев» (британский писатель индийского происхождения С. Рушди), «историей разочарования», «перемыванием собственных внутренностей» 
(В. Набоков), «дуэлью, почти войной, упражнениями в страдании» (испанский писатель А. Гомес-Аркос), «предательством» (галисийский автор Э. Бланко-Амор) и т. д.

Английский писатель, поэт и переводчик К. Уайт в статье «Против авторского перевода» настаивает, что для него подобная деятельность всегда связана с давлением, а не с удовольствием или удовлетворением [20, с. 67]. Он также обращает внимание на языковой аспект АП, при котором «один язык стремится занять место другого» [20, с. 69].

Почему же АП продолжает существовать, несмотря на очевидные затруднения, которые он приносит своим сторонникам? Исчерпывающий ответ на этот вопрос дает канадская писательница Н. Хьюстон: «...когда работа окончена, я чувствую себя исцеленной, потому что это та же самая книга, она рассказывает ту же историю, вызывает те же эмоции, слышится та же музыка»[17, с. 57]. С позиций профессионализма АП ведет «к совершенствованию стиля, к обогащению образности языка» [11, с. 139], заставляет по-новому, более критично взглянуть на свое творчество, перевести его на новый уровень [11, с. 152].

Причины обращения к АП многообразны и индивидуальны для каждого писателя. Существующие классификации данных факторов в одних случаях недостаточно раскрыты (М. А. Антунес (Бразилия), М. Апышев, Г. Рабаков (Молдавия), Ю. И. Сикалюк (Россия), Н. В. Яковенко (Денисова) и др.), а в других - слишком раздроблены (Е. С. Хованская и О. В. Праченко (Россия)), Проанализировав и обобщив их, мы составили собственную классификацию причин, по которым авторы переводят свои произведения самостоятельно.

В первую группу входят внешние факторы. Как правило, это социально-политические и идеологические причины (эмиграция писателей, смена культурно-языковой обстановки, длительное пребывание в чужой языковой среде, давление цензуры), которые способствовали появлению АП С. Аттар (Сирия - Канада - США - Алжир - Австралия), И. Бродского (Россия - США), А. Дорфмана (Аргентина Чили - США), В. Козового (Россия - Франция), В. Набокова (Россия США), Н. ва Тхионго (Кения - Англия) и др. Украинский писатель Г. Ф. Квитка-Основьяненко занимался АП с целью «утвердить гражданский статус украинского слова» [13, с. 94]. Кроме того, заняться переводом своих произведений писателей побуждают такие причины, как отсутствие переводчиков с определенной комбинацией языков, коммерческие интересы и проч.

Ко второй группе мы относим внутренние (индивидуальные) факторы:

1.Некоторые авторы желают сразу получить перевод оптимального качества, который полностью раскрывал бы идею оригинального текста, 
сохраняя его особенности. Об этом говорит азербайджанский писатель Анар: «Мои авторские переводы - отнюдь не самонадеянная попытка выразить адекватно на русском языке текст оригинала. Им лучше владеют мои переводчики. Но я лучше их владею языком оригинала, и моя попытка автоперевода все же в какой-то степени вызвана стремлением сохранить и передать особенности, нюансы оригинала» [11, с. 157]. Подобных убеждений придерживались И. Бродский, испанский переводчик Х. М. Рамис и др.

2. Нередко профессиональные переводы не отражают особенности авторского стиля (как в случае В. Быкова), что, возможно, подталкивает писателей заняться АП. Этот факт свидетельствует не только о стремлении получить качественный перевод, но и о неудовлетворенности уже существующими. Например, белорусский прозаик И. Мележ был недоволен авторизованными переводами Л. Шапиро и Л. Раковского, поэтому обратился к АП. Кроме того, недовольство качеством переводов, выполненных профессиональными переводчиками, сподвигло к АП И. Бродского, В. Набокова, а также армянского поэта и прозаика Н. Зарьяна и многих белорусских авторов (В. Быкова, В. Вербу, К. Крапиву, А. Макаенка, М. Рыльского и др.) [13, с. 94-95].

3. Автор испытывает глубокое чувство ответственности перед своими произведениями и поэтому берется за их перевод. Так, говоря о причинах самостоятельного перевода повести «Суд у Слабадзе», В. Козько отмечал: «Повесть о Белоруссии, на белорусском материале, в какой-то степени и о моих истоках сама потребовала и языка. И никому, естественно, я не мог доверить ее перевод» [11, с. 149].

4. Естественное для любого автора желание донести свое творчество до более широкого круга читателей, получить всеобщее признание отмечали в качестве причины АП русский и киргизский писатель Ч. Айтматов; баскский писатель Б. Ачага; киргизский автор М. Байджиев; азербайджанский и русский писатель, переводчик Ч. Г. Гусейнов; русский прозаик, драматург, переводчик А. Ким и др. [2; 11; 15].

5.В. Набоков, Ч. Айтматов рассматривали АП как средство творческого самосовершенствования [2; 15].

6. Необходимостью творческого самовыражения не только на первом, но и на «втором родном языке» объясняют АП, например, М. Байджиева [2, c. 106$]$.

7. Кроме того, обращение к АП подразумевает чувства патриотизма, ностальгии, глубокой любви к родине [15].

8.Причиной АП может стать интерес автора к новой для него деятельности, разовый эксперимент (как в случае Анара) [2, с. 107]. 
9. Желание ознакомить со своими произведениями конкретных людей, не владеющих языком оригинала, обусловило появление АП Е. Баратынского, М. Богдановича [13, с. 94].

10. Французский и испанский писатель X. Семпрун указывал в качестве причины обращения к АП неудовлетворенность первой версией произведения, желание изменить, дополнить исходный текст [18, с. 162].

Безусловно, автор может испытывать воздействие нескольких факторов одновременно, однако все они служат предпосылкой для появления такого перевода, который максимально согласуется с авторским замыслом и раскрывает идею, заложенную в оригинале. В тех случаях, когда автор и переводчик художественного текста представлены одной языковой личностью, могут иметь место «правомерные» и «неправомерные» изменения, вносимые в текст перевода.

К первым мы относим, вслед за В.П. Рагойшей и другими лингвистами, «добавления», «улучшения», «украшения», на которые не имеет права профессиональный переводчик [13, с. 100-101]. В соответствии с теорией скопоса К. Райс и Х. Фермеера, апелятивные тексты, ориентированные на обращение к читателю, должны не только передавать смысл, но и нести определенный экстралингвистический эффект. Верность оригиналу заключается в достижении эффекта, аналогичного эффекту оригинала, в другой культурно-языковой аудитории. При этом переводчик может отклоняться от содержания и формы оригинала [9, с. 80].

Словацкий лингвист А. Попович выделяет три формы отношений между переводчиком и читателем: читатель не владеет языком оригинала и воспринимает перевод как первичный текст (наиболее распространенный случай); читатель владеет языком оригинала, может оценить качество перевода, воспринимает перевод как вторичный текст, производный от оригинала; читатель выступает в роли активного участника процесса перевода, поскольку переводчик ориентируется на его восприятие при выборе языковых и художественных средств [12, с. 69]. Несмотря на то что последняя форма отношений встречается, согласно А. Поповичу, реже всего, в случае АП она часто преобладает: потенциальный читатель навязывает автору-переводчику свои языковые, национальные, вкусовые особенности - все то, что побуждает его к изменениям при переводе [14, с. 33].

Отличительная черта АП заключается в том, что данный процесс происходит в пределах единого сознания творческой билингвальной языковой личности, когда автор сознательно становится читателем собственного текста, активизируя механизмы билингвизма и автокоммуникации. Очевидно, те же механизмы способствуют проявлениям межъязыковой интерференции - явления, которое мы 
относим числу «неправомерных» изменений в процессе авторского перевода. Следует, однако, уточнить, что интерференция может быть свойственна любому переводу, поскольку каждый переводчик, даже если он не является автором оригинального текста, представляет собой билингвальную языковую личность. Под интерференцией понимают процесс и результат контакта языковых систем в речи билингва, при котором одна система является доминирующей, порождающей эффект воздействия во вторичной, приобретенной языковой системе [6, с. 24-25].

Результатом неверного выбора языковых средств становятся нарушения на фонетическом, лексико-семантическом, морфологическом, синтаксическом и стилистическом уровнях, которые соотносятся с лингвистическим аспектом двуязычия. Ученые видят языковую проблему билингвизма в том, чтобы «предсказать наиболее вероятные проявления интерференции <..>> и указать отклонения от норм каждого из языков» [5, c. 144]. Изучение особенностей межъязыковой интерференции может проводиться в условиях взаимодействия близкородственных либо далеких языков, однако в обоих случаях лингвистическая составляющая АП является значимым и перспективным этапом в исследовании феномена билингвизма.

В итоге попытаемся сформулировать основные принципы лингвистического подхода к авторскому переводу.

1.С языковой точки зрения, АП является разновидностью перевода, поскольку его отождествление с новой редакцией, творческим переосмыслением, воссозданием либо вариантом оригинального произведения, так же как его уникальный статус или синкретичный подход подразумевают смысловые, сюжетные изменения, которые входят в компетенцию литературоведения.

2. Билингвальная языковая личность автора-переводчика обладает особым типом мышления и постоянно находится в состоянии внутреннего конфликта, обусловленного необходимостью выбора одной из двух языковых систем, работу которых контролируют разные зоны головного мозга, с целью адекватного речевого поведения.

3. Причины обращения к АП в каждом случае носят индивидуальный характер. Под воздействием комплекса внешних и внутренних факторов автор стремится к созданию такого перевода, который максимально раскрывает идею, заложенную в оригинале.

4.В случае самостоятельного перевода своих произведений автор может вносить в текст «правомерные» и «неправомерные» изменения. Первые из них преимущественно относятся к литературоведческой области изучения АП, так как затрагивают сюжетную сторону текста. Лингвистический анализ АП, очевидно, должен включать изучение 
проявлений межъязыковой интерференции, что может внести существенный вклад в исследование феномена билингвизма.

\section{СПИСОК ИСПОЛЬЗОВАННОЙ ЛИТЕРАТУРЫ}

1. Андреева, С. В. Билингвизм и его аспекты / С. В. Андреева // Ученые записки Забайкальского государственного гуманитарно-педагогического университета им. Н. Г. Чернышевского. Сер. Филология, история, востоковедение. - 2009. № 3 (26). - С. 34-38.

2. Апышев, М. Феномен двуязычия : Чингиз Айтматов и Мар Байджиев : научнопопулярное издание / М. Апышев. - Б. - 2009. - 156 с.

3. Башкова, И. С. Нейропсихологическая характеристика билингвизма / И. С. Башкова, И. Г. Овчинникова // Вопросы психолингвистики. - 2013. № 17. - С. 53-69.

4. Блягоз, 3. У. Контактирование русского и родного языков в условиях двуязычия : учебное пособие / 3. У. Блягоз. - Ростов-на-Дону : Изд-во Ростовского пед. ин-та, 1976. - 76 с.

5. Вайнрайх, У. Языковые контакты : состояние и проблемы исследования / У. Вайнрайх. - Киев : Вища школа, 1979. - 263 с.

6. Вишневская, Г. М. Билингвизм и его аспекты : учебное пособие / Г. М. Вишневская. - Иваново, 1997. - 99 с.

7. Выготский, Л. С. Умственное развитие детей в процессе обучения : сб. ст. / Л. С. Выготский. - М. - Л. : Государственное учебно-педагогическое издательство, 1935. - 136 с.

8. Гируцкий, А. А. Белорусско-русский художественный билингвизм : типология и история, языковые процессы / А. А. Гируцкий. - Мн. : Университетское, 1990. - 175 c.

9. Комиссаров, В.Н. Общая теория перевода : проблемы переводоведения в освещении зарубежных ученых / В. Н. Комиссаров. - М. : Черо, 1999. - 136 с.

10. Марина, О. А. Некоторые современные модели порождения речи у билингвов: условия и степень взаимовлияние языков в данных моделях / О. А. Марина // Язык и коммуникация в контексте образования и культуры : сб. науч. тр. / Тверской гос. ун-т ; отв. ред. Л. Рыжова. - Тверь, 2012. - Вып. 4. - С. 99-113.

11. Михайловская, Н. Г. Путь к русскому слову / Н. Г. Михайловская. - М. : Наука, 1986. - $176 \mathrm{c}$.

12. Попович, А. Проблемы художественного перевода / А. Попович. - М. : Высшая школа, 1980. - 200 с.

13. Рагойша, В. П. Проблемы перевода с близкородственных языков : белорусскорусско-украинский поэтический взаимоперевод / В. П. Рагойша. - Мн. : Изд-во БГУ, 1980. - 184 с.

14. Сикалюк, Ю. И. Способы воспроизведения индивидуального стиля Ивана Франко в автопереводах (на материале немецкого и украинского языков) : дис. ... канд. филол. наук : 10.02.20 / Сикалюк Юлия Игоревна. - М., 2015. $231 \mathrm{c}$.

15. Хованская, Е. С. Авторский перевод. Причины обращения / Е. С. Хованская, О. В. Праченко // Политематический сетевой электронный научный журнал Кубанского государственного аграрного университета (Научный журнал КубГАУ) [Электронный ресурс]. - Краснодар : КубГАУ, 2014. - № 05 (099). - 
Режим доступа : http://ej.kubagro.ru/2014/05/pdf/96.pdf. - Дата доступа : 31.01.2016.

16. De Roubaix, L. Where boundaries blur: André Brink as writer, bilingual writer, translator and selftranslator / L. De Roubaix // Versatility in Translation Studies : Selected Papers of the Cetra Research Seminar in Translation Studies [Electronic resource]. - 2012. - Mode of access : https://www.arts.kuleuven.be/ cetra/papers/files/de-roubaix.pdf. - Date of access : 31.01.2016.

17. Falceri, G. Nancy Huston, Self-Translation and a Transnational Poetics / G. Falceri // Ticontre. Teoria Testo Traduzione. - 2014. - № 2. - P. 51-66.

18. López L.-Gay, P. Conversación con Jorge Semprún. Sobre autotraducción. De los recuerdos y sus formas de reescritura / P. López L.-Gay // Quaderns : Revista de traducció. - 2008. - № 16. - P. 157-164.

19. Mohdeb, Y. L'autotraduction littéraire, entre traduction et réécriture, le cas de Rachid Boudjedra / Y. Mohdeb [Electronic resource]. - Mode of access : http://www.academia.edu/6156621/Lautotraduction_litt\%C3\%A9raire_entre_traducti on_et_r\%C3\%A9\%C3\%A9criture_le_cas_de_Rachid_Boudjedra. - Date of access : 31.01.2016.

20. Whyte, C. Against Self-Translation / C. Whyte // Translation and Literature. 2002. - № 11/1 (Spring). - P. 64-76.

Стаття надійшла 04.02.2016 року

УДК 81’373.234

Алексей Романчук

(Кичинев, Молдова)

\section{*СТЛАВЕНЕ КАК ИСХОДНАЯ ФОРМА ЭТНОНИМА ‘СЛАВЯНЕ’: КОНТУРЫ ГИПОТЕЗЫ}

В статье предлагается обоснование предложенной ранее автором новой этимологии этнонима славяне. Учитывая постулируемый В.В.Мартыновым «италийский ингредиент» в праславянском глоттогенезе, а также ряд других фактов, автор предлагает связывать этноним славяне с производными индоевропейского *stl- 'стелить, расстилать' - как уже предлагалось ранее для этнонима латины.

Ключевые слова: славяне, балты, этимология, склавины, латиныл.

Romanchuk A. A. *Stlavene as a primary form of ethnonym 'Slavs': a scketch of hypothesis.

The article suggest an argumentation of new etymology of ethnonym 'Slavs'. Basing on the conclusion of $V$. V. Martynov about "Italic ingredient" of for-Slavic glottogenesys, as well as taking into account some other important facts, the author suppose that the ethnonym 'Slavs' could be considered as a derivate of i.-e. *stl- 'lay, spread' (as it was earlier suggested for ethnonym 'Latins'.

Keywords: Slavs, Balts, etymology, Sklavinians, Latins. 